\title{
Evidence for an Instructive Role of Retinal Activity in Retinotopic Map Refinement in the Superior Colliculus of the Mouse
}

\author{
Anand R. Chandrasekaran, ${ }^{1}$ Daniel T. Plas, ${ }^{1}$ Ernesto Gonzalez, ${ }^{1}$ and Michael C. Crair ${ }^{1,2}$ \\ ${ }^{1}$ Department of Neuroscience and ${ }^{2}$ Program in Developmental Biology, Baylor College of Medicine, Houston, Texas 77030
}

\begin{abstract}
Although it is widely accepted that molecular mechanisms play an important role in the initial establishment of retinotopic maps, it has also long been argued that activity-dependent factors act in concert with molecular mechanisms to refine topographic maps. Evidence of a role for retinal activity in retinotopic map refinement in mammals is limited, and nothing is known about the effect of spontaneous retinal activity on the development of receptive fields in the superior colliculus. Using anatomical and physiological methods with two genetically manipulated mouse models and pharmacological interventions in wild-type mice, we show that spontaneous retinal waves instruct retinotopic map refinement in the superior colliculus of the mouse. Activity-dependent mechanisms may play a preferential role in the mapping of the nasal-temporal axis of the retina onto the colliculus, because refinement is particularly impaired along this axis in mutants without retinal waves. Interfering with both axon guidance cues and activity-dependent cues in the same animal has a dramatic cumulative effect. These experiments demonstrate how axon guidance cues and activity-dependent factors combine to instruct retinotopic map development.
\end{abstract}

Key words: retinotopy; retinal waves; superior colliculus; $\beta 2$ subunit of nicotinic acetylcholine receptor; in vivo physiology; BMP

\section{Introduction}

The brain represents the world around us in the form of sensory maps. To construct these maps, the spatial relationship between sensory neurons needs to be maintained at their target. Mechanisms involved in the guidance of axons in the developing brain and the subsequent refinement of connections to establish precise topographic relationships are still under intense investigation. Both molecular and activity-dependent factors are believed to play important roles in the formation of visual maps (Cline, 2003). In the development of retinotopic maps, for instance, chemical cues appear to dominate early in map formation, laying down the initial coarse topography of the retina onto the superior colliculus (SC) (Sperry, 1963). Activity-dependent factors then guide map refinement (Katz and Shatz, 1996; Crair, 1999). These ideas have been tested with some success in lower vertebrates (Debski and Cline, 2002), but they are difficult to test in the mammalian visual system, and important differences may exist between species. The mouse offers an excellent compromise between the competing desires of understanding a visual system like

Received April 14, 2005; revised June 22, 2005; accepted July 8, 2005.

This work was supported by National Institutes of Health Grants R01 MH62639, T32 EY07001, and EY15788 as well as by grants from the Klingenstein, Merck, and Sloan Foundations and the American Heart Association and National Alliance for Research on Schizophrenia and Depression. We gratefully acknowledge John Maunsell, David Sparks, and Bill Bosking for helpful discussions and comments on this manuscript. We also thank A. Beaudet for the $\beta 2$ mutant mice, Paul Overbeek for the BMP transgenic mice, and G. Eichele and C. Thaller for early access to the $\beta 2$ in situs available at www.genepaint.org.

Correspondence should be addressed to Michael C. Crair, Department of Neuroscience, Baylor College of Medicine, One Baylor Plaza S-603, Houston, TX 77030. E-mail: mcrai@@bcm.tmc.edu.

DOI:10.1523/JNEUROSCI.1470-05.2005

Copyright $\odot 2005$ Society for Neuroscience $\quad$ 0270-6474/05/256929-10\$15.00/0 that in humans and having the necessary molecular and genetic tools for mechanistic studies of development.

More than 40 years have passed since Sperry (1963) hypothesized that chemical factors mediate the mapping of retinal ganglion cells (RGCs) onto their tectal (colliculus in mammals) target. It was only recently that molecular players were actually identified and the role of specific receptor-ligand families of axon guidance molecules was characterized in this process (Flanagan and Vanderhaeghen, 1998; O'Leary et al., 1999). Evidence for activity in the development of retinotopy has comparatively languished (Simon et al., 1992; Huang and Pallas, 2001), and, only recently, spontaneous retinal activity was shown to play a role in the anatomical development of retinal ganglion cell arbors in the colliculus (McLaughlin et al., 2003b).

We describe anatomical and physiological experiments using mutant and transgenic mice as well as pharmacological manipulations in wild-type (WT) mice that reveal the consequences of eliminating retinal waves on the development of retinotopy in the colliculus. We first confirm that spontaneous retinal waves are necessary for the anatomical refinement of retinal ganglion cell arbors, which normally occurs in the first week after birth. We then show in double-mutant mice, which lack retinal waves and also have axon guidance defects, a dramatic cumulative effect of eliminating both chemotropic and activity-dependent factors on retinotopic map refinement. Finally, we demonstrate in vivo how physiological receptive fields (RFs) are altered by the absence of neonatal retinal waves during development. This work illustrates the physiological consequences of eliminating retinal waves on the development of retinotopy in the colliculus and also provides 
the first demonstration of the combined role of chemotropic and activity-dependent factors on the development of retinotopy.

\section{Materials and Methods}

Mutant mice. Mice lacking the $\beta 2$ subunit of the nicotinic acetylcholine receptor (nAChR) were generated in the Beaudet laboratory (Baylor College of Medicine), back-crossed at least six generations onto the C57BL/6 background and genotyped as described previously (Xu et al., 1999). Bone morphogenetic protein (BMP) transgenic mice used in this study were homozygous for the BMP transgene (lens-specific $\alpha \mathrm{A}$-crystallin promoter driving expression of human BMP2 cDNA), generated in the Overbeek laboratory, and back-crossed eight generations onto the C57BL/6 background and genotyped as described previously (Hung et al., 2002).

Dye injections. Focal injections of the lipophilic dye $1,1^{\prime}$-dioctadecyl$3,3,3^{\prime}, 3^{\prime}$-tetramethylindocarbocyanine perchlorate (DiI) (4.6 or $9.2 \mathrm{nl}$ with Nanoject; Drummond Scientific, Broomall, PA) were made into dorsal-nasal neonatal [postnatal day 6 (P6)-P7, P14-P16, or P19-P20] mouse retinas. The injected pups were allowed to recover from the anesthesia and were put back with their mother for $48 \mathrm{~h}$ to allow transport of the tracer from the retina to the SC. The pups were anesthetized using an intraperitoneal injection $(0.7 \mathrm{ml} / \mathrm{kg})$ of a combination anesthetic (in $\mathrm{mg} / \mathrm{ml}$ : 4.28 ketamine, 0.82 xylazine, and 0.07 acepromazine). The animals were then killed, and the entire brain was dissected and put in a combination of either $5-7$ drops of $10 \%$ formamide in $2 \mathrm{ml}$ of $1 \times$ PBS or $50 / 50$ of $1 \times \mathrm{PBS} / 4 \%$ PFA. The SC was exposed by carefully removing the overlying cortex and was photographed under fluorescent illumination using a CCD camera and associated software (Epix, Houston, TX). The gain (in decibels), offset (in percentage), and exposure (in seconds) were adjusted to minimize the background but keep the outline of the SC visible. Retinal dye injections were localized along the perimeter of the retina (supplemental figure, available at www.jneurosci.org as supplemental material), using as a reference the insertion points of the four major eye muscles (Plas et al., 2005). The retina was then removed and carefully filleted, and digital images of the retinal flat mount were acquired with a CCD camera.

Quantification of fluorescent images. Quantification of "target zone" projections to the colliculus followed previously published methods (Plas et al., 2004) and were performed blind to the genotype of the animal. Briefly, the SC was outlined manually, and a point within the SC, but far from the labeled target in the SC, was chosen as background level. The background was subtracted from the image, and a threshold was set at one-half of the maximum fluorescent signal. The area above threshold was taken to be the target area labeled by the injection. Results are reported as the ratio of target area to total SC area (in percentage). The anatomical projection ratio [rostral-caudal (RC) to medial-lateral (ML) target zone extent] was measured from the half-max thresholded target area. Quantification of retinal injection size was performed by measuring the area of fluorescent signal in the retina above one-half of the maximum fluorescent signal after background subtraction. Errors are SEM.

Epibatidine treatment. Vitreal injections of epibatidine $(0.5 \mu \mathrm{l} ; 2 \mathrm{~mm}$ in physiological solution) were made in one eye, while vehicle control ( 0.5 $\mu \mathrm{l}$ ) was injected in the other eye of mice every $24 \mathrm{~h}$ from P3-P7. The mice were allowed to recover from anesthetic each day and were returned to their mother. At P8, focal DiI injections were made in the dorsal-nasal retina of both eyes. After $48 \mathrm{~h}$, the animals were killed, and the colliculus was exposed for photography under fluorescent illumination and quantification of target zone areas, as described previously.

In vivo electrophysiology. Mice (5-7 weeks of age) from $\beta 2^{+/-}$breeding pairs were used blind to the genotype. Mice were anesthetized by allowing them to breathe $1.5 \%$ isoflurane in a mixture of $\mathrm{N}_{2} \mathrm{O}$ and $\mathrm{O}_{2}$ (2:3) and then mounting them in a custom-made stereotaxic apparatus using ear bars. A modified gas mask provided additional stability while allowing full viewing of visual stimuli. Body temperature was monitored using a rectal probe and was maintained using a heating pad (Harvard Apparatus, Holliston, MA). Heart rate was monitored continuously throughout the experiment. A craniotomy $\left(4 \mathrm{~mm}^{2}\right)$ was performed to expose the cortex overlying the SC. A tungsten electrode (1-5 M 2 ; FHC, Bowdoinham, ME) was lowered into the brain using a micromanipulator
(Newport, Irvine, CA), until visual responses were detected to wholefield stimuli. The center of the RF was identified by a hand-controlled stimulus on the monochrome monitor (Vision Research Graphics, Durham, NH) placed in front of the mouse. The position of the monitor was then adjusted for optimal coverage of the RF. Electrical signals were bandpass filtered $(0.3-5 \mathrm{kHz})$ and amplified (10,000×; A-M Systems, Sequim, WA) before being captured on a computer using an analog-todigital card ( $25 \mathrm{kHz}$; National Instruments, Austin, TX).

Stimulus presentation. The stimuli were controlled using a VSG 2/5 card (Cambridge Research Systems, Kent, England). The individual stimuli were light squares $\left(7-12 \mathrm{~cd} / \mathrm{m}^{2}\right)$ presented for $300 \mathrm{~ms}$ on a dim background $\left(0.5-1 \mathrm{~cd} / \mathrm{m}^{2}\right)$, followed by a gap of $450 \mathrm{~ms}$ before the next stimulus presentation. Spatially overlapping stimuli were presented in pseudorandom order to form a grid in visual space. The sizes of the stimuli were adjusted to have similar sampling densities at each recording site (3-7 stimuli across the RF along each axis). The sequence was rerandomized and repeated 3-5 times to get an average response.

Electrolytic lesions. At the end of each session, a lesion $(3 \mu \mathrm{A} ; 3 \times 1 \mathrm{~s})$ was made to identify the location of the recording site. The animal was killed by an overdose of a rodent combination anesthetic (in mg/ml: 4.28 ketamine, 0.82 xylazine, and 0.07 acepromazine). The brain was removed and fixed in $10 \%$ formalin overnight. Coronal sections $(80 \mu \mathrm{m})$ were made to verify that the recording was from the superficial SC.

Data analysis. To extract multiunit activity from voltage traces, a spike threshold was set at three times the SD of the sampled voltage. The number of spikes (action potentials) was counted to calculate the response to each stimulus. Spikes occurring in the first 50-350 ms after turning the stimulus $\mathrm{ON}$ were binned as part of the $\mathrm{ON}$ response of the cell, and subsequent spikes (350-750 ms) were binned into the OFF response. Receptive fields were separately characterized for the $\mathrm{ON}$ and OFF response, but no difference was detected in any of the genotypes (data not shown). The receptive fields of cells at each recording location were determined from the averaged response to stimuli at each stimulus location. Only those recording sites with responses that were significantly greater than background spontaneous activity (at $p<0.01$ ) in at least four contiguous stimulus locations were included for additional analysis. Results are presented as mean \pm SEM and are considered significant when $p<0.05$; $t$ test was used unless otherwise stated.

Voltage traces were analyzed to determine whether single cells could be isolated from the recorded multiunit activity. A software window discriminator that sorted action potential waveforms according to shape and amplitude was used to isolate single units. Only cases with clear and obvious separation of voltage waveforms by visual inspection were considered to be isolated single units.

To calculate the peak response, an oriented two-dimensional (2D) (elliptical) Gaussian was fit to the acquired data (Tavazoie and Reid, 2000) after background subtraction. Background spontaneous activity was uniformly low, on average $0.93 \pm 0.2 \mathrm{~Hz}$, with no difference between genotypes. The quality of the Gaussian fit was examined using Pearson's regression coefficient $(r)$ between the raw data and the fit elliptical Gaussian. Only $r^{2}>0.5$ was considered well fit by the Gaussian.

To quantify RF area and volume, responses to stimulus locations that were $>37 \%$ of the peak response were summed. The total response was similarly calculated by integrating all responses $>37 \%$ of the peak response. Some receptive fields were not well fit with a Gaussian; therefore, as an alternate measure, we calculated the area and volume of all receptive fields using $37 \%$ of the strongest average response to an individual stimulus location as a threshold rather than $37 \%$ of the calculated peak response from the Gaussian fit.

\section{Results \\ Retinal ganglion cell arbors in the superior colliculus fail to refine in $\beta 2^{-/-}$mice}

The developing vertebrate retina is spontaneously active, with epochs of traveling waves of neuronal activity that traverse it in apparently random direction and time. These waves initially require $\mathrm{nAChRs}$ for their propagation during a short period of development that corresponds to the first week after birth in mice 

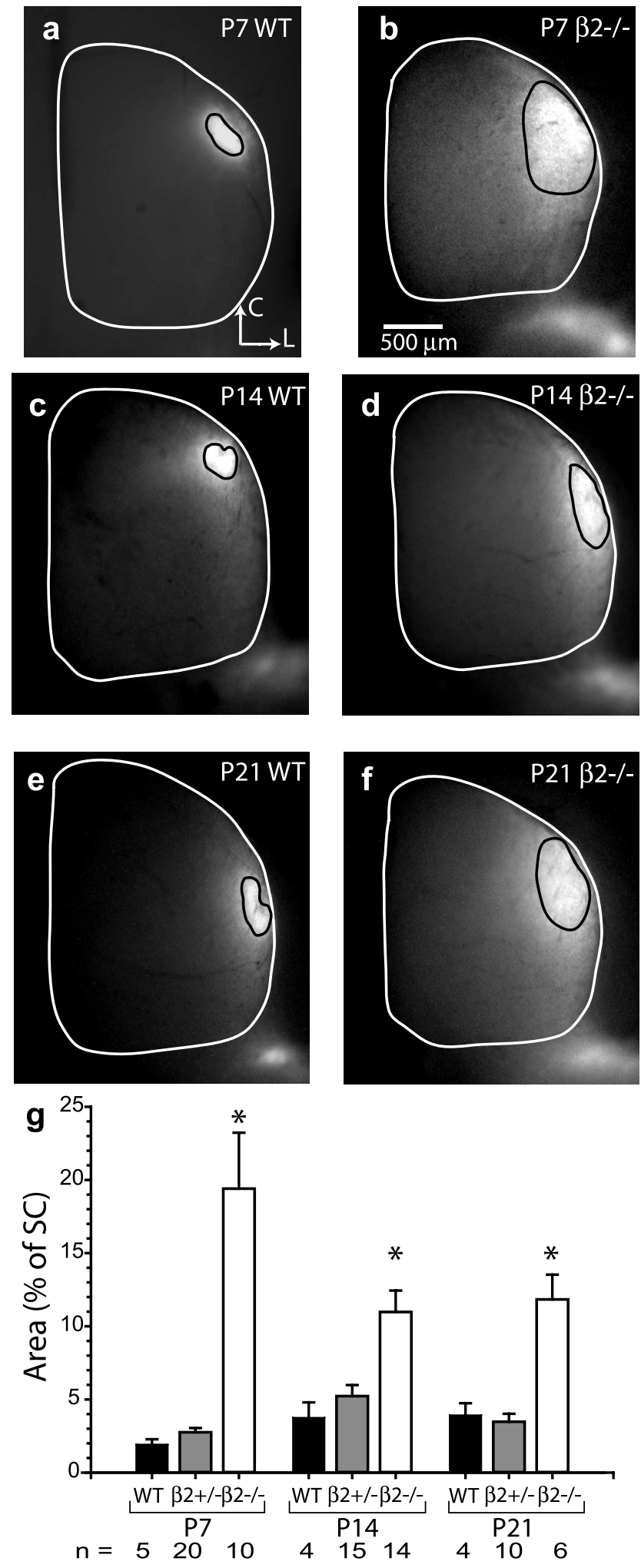

Figure 1. $\quad \beta 2^{-1-}$ mice have enlarged retinocollicular projections. $\boldsymbol{a}, \boldsymbol{c}, \boldsymbol{e}$, Examples of focal dye injections in the retina that result in focal spots of label (target zones; outlined in black) in the contralateral SC (outlined in white) of mice. Typical projections in P7, P14, and P21 WT SC.b, $\boldsymbol{d}, \boldsymbol{f}$, Typical projections in $\beta 2^{-/-}$mice at corresponding ages. $\boldsymbol{g}$, Summary of quantified projection area for all ages and genotypes. WT (white bars) and heterozygous ( $\beta 2^{+-}$; gray bars) mice have similar projection areas at all time points. $\beta 2^{-1-}$ (black bars) mice have larger projection ratios at all time points compared with WT or $\beta 2^{+/-}$mice. There is a partial rescue after the onset of glutamatergic retinal waves in the second week after birth but no additional rescue after the onset of visual experience at approximately P14 ( $t$ test; $\left.{ }^{*} p<0.05\right)$. Error bars represent SEM. and then switch for another week to a reliance on glutamate as neurotransmitter. Pharmacological experiments and analysis of mice with mutations in various elements of the nAChR identify the $\beta 2$ subunit as a necessary component of the receptor for the propagation of retinal waves (Feller, 2002).

We examined the retinocollicular projection in $\beta 2^{-1-}$ mice, which lack patterned waves of retinal activity during the first week after birth (Bansal et al., 2000; McLaughlin et al., 2003b). After a focal injection of DiI into the retina, the dye is incorporated by a small group of RGCs and transported to the SC, permitting a description of the distribution of labeled RGC axon arbors (Fig. 1a). The labeled spot in the SC is large early in postnatal development and becomes progressively smaller as the animals age and as RGC axon arbors refine, with projections in WT mice reaching their adult-like state by P8 (Simon and O'Leary, 1992). Focal retinal injections on P6/7 into dorsal-nasal retina in both $\beta 2^{-1-}$ mice and their WT littermates resulted in labeled spots in the caudal-lateral colliculus $48 \mathrm{~h}$ later (Fig. 1 $a, b$ ). Correspondingly, injections into ventral-temporal retina resulted in labeled spots in the rostral-medial SC (data not shown) in WT and $\beta 2^{-l-}$ mice, suggesting that gross retinotopy is unperturbed in the $\beta 2^{-1-}$ mice. We measured the area of the SC target spot after stereotyped dorsal-nasal injections (Plas et al., 2004). Focal injections in WT and $\beta 2^{+/-}$mice resulted in a label that spanned a small fraction of the area of the colliculus (WT, $1.91 \pm 0.36 \%$, $\left.n=5 ; \beta 2^{+/-}, 2.75 \pm 0.3 \%, n=20\right)$. The area of SC labeled in the $\beta 2^{-1-}$ mice was significantly larger $\left(\beta 2^{-1-}, 19.4 \pm 3.8 \%, n=\right.$ $10)$ than WT and $\beta 2^{+/-}$littermates $(p<0.01)$ (Fig. $\left.1 g\right)$. The variation in the relative area of the SC labeled between the different genotypes was not attributable to a systematic difference in the size of the retinal injections (WT and $\beta 2^{+/-}, 0.066 \pm 0.011$ $\left.\mathrm{mm}^{2}, n=11 ; \beta 2^{-1-}, 0.070 \pm 0.015 \mathrm{~mm}^{2}, n=5\right)$ nor to a difference in the total area of the SC (WT, $2.79 \pm 0.10 \mathrm{~mm}^{2}, n=$ $5 ; \beta 2^{+/-}, 2.72 \pm 0.13 \mathrm{~mm}^{2}, n=20 ; \beta 2^{-l-}, 2.20 \pm 0.34 \mathrm{~mm}^{2}$, $n=10 ; p>0.25$ for all comparisons). Thus, although gross retinotopy appears normal, RGC projections to the superior colliculus failed to refine in $\beta 2^{-/-}$mice.

\section{Partial rescue of refinement during the second week}

Retinal waves in $\beta 2^{-/-}$mice resume at approximately P8 and persist until eye opening 1 week later (Bansal et al., 2000). We therefore measured the size of the SC projection zones at $\mathrm{P} 14$ and $\mathrm{P} 21\left(\mathrm{P} 14 \beta 2^{-/-}, 10.97 \pm 1.46 \%, n=14 ; \mathrm{P} 21 \beta 2^{-/-}, 11.83 \pm\right.$ $1.69 \%, n=6)$ to determine whether retinotopic refinement improves in $\beta 2^{-/-}$mice after the initiation of retinal waves in the second week after birth (Fig. 1a-f). By P14, the target spot size was significantly smaller than at P7 (43\% reduction in area between P7 and P14; $p<0.05)$, but it did not shrink thereafter ( $p=$ 0.73 for comparison between P14 and P21). At all ages, the target spot size was significantly larger $(p<0.01)$ in $\beta 2^{-/-}$mice than in littermate controls (P14 WT, $3.84 \pm 1.06 \%, n=4$; P14 $\beta 2^{+/-}$, $5.23 \pm 0.76 \%, n=15 ; \mathrm{P} 21 \mathrm{WT}, 3.91 \pm 0.83 \%, n=4 ; \mathrm{P} 21 \beta 2^{+/-}$, $3.47 \pm 0.55 \%, n=10)$.

\section{Cumulative effect of axon guidance defects and the} elimination of retinal waves on development of retinotopic maps

Interfering with molecular cues responsible for targeting RGC axons to the colliculus, such as that which occurs in mutants of the Eph/ephrin signaling pathway (Feldheim et al., 2000, 2004), typically causes the formation of one or more "ectopic spots," which are formed by the dense arbors of a small number of misdirected RGC axons. One such mutant is a transgenic that over- 

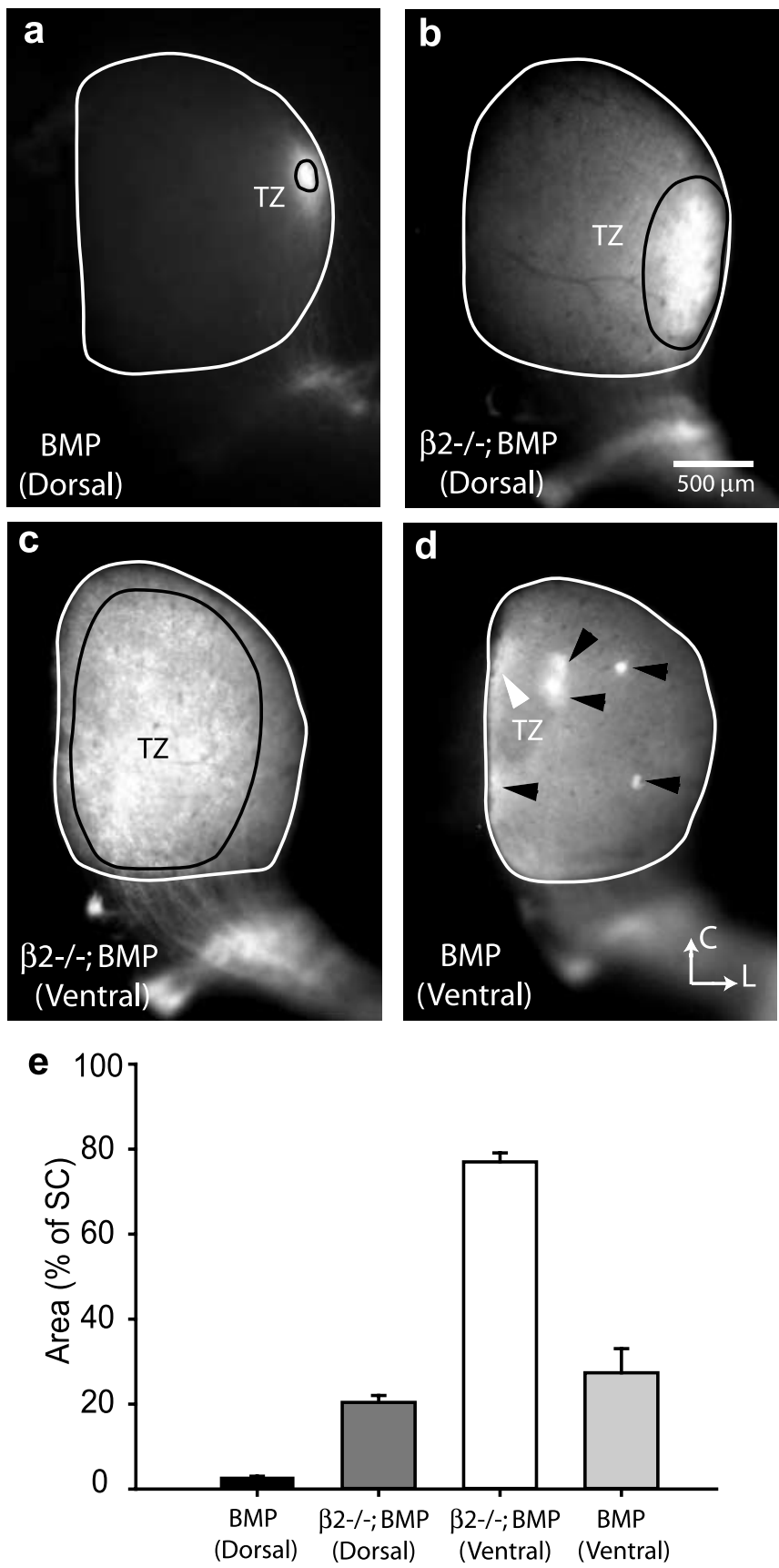

Figure 2. Molecular and activity-dependent mechanisms combine to guide retinotopic map development in the SC. $\boldsymbol{a}$, A focal retinal injection into the dorsal retina of a BMP transgenic mouse (P6 - P7) results in a single normal confined target zone in lateral colliculus. $\boldsymbol{b}$, In BMP transgenics that are also homozygous for the $\beta 2$ mutation, dorsal retinal injections result in large target zones. c, A focal retinal injection into ventral retina of a BMP transgenic that is also homozygous for the $\beta 2$ mutation results in a very large, completely unrefined pattern of projection to the SC. $\boldsymbol{d}$, A ventral retinal injection into a BMP mutant results in a normal target zone in the medial colliculus (white arrowhead) as well as numerous ectopic spots (black arrowheads), typical of mutant mice with disturbed molecular cues responsible for establishing retinotopic maps in the colliculus. $\boldsymbol{e}$, Quantification of the target zone area for the various genetic backgrounds and retinal injection sites. Dorsal injections into the BMP transgenic retina (black bar) have a completely normal target zone location and area, as is expected. Crossing the BMP mice onto a $\beta 2^{-1-}$ background $\left(\beta 2^{-1-} ; \mathrm{BMP}\right)$ causes an enlarged target zone, attributable to the absence of retinal waves (dark gray bar). Ventral injections into the retina of BMP mice on the $\beta 2^{-I-}$ background $\left(\beta 2^{-I-} ; \mathrm{BMP}\right.$ ) results in projections that nearly fill the SC (white bar). This demonstrates that focal ectopic spots, which normally result from ventral injections in BMP mice, are the result of the influence of retinal waves in the first week after birth $[p<0.0001$ for difference between BMP (Dorsal); $\beta 2^{-1-} ; \mathrm{BMP}$ (Dorsal), and $\beta 2^{-/-} ; \mathrm{BMP}$ (Ventral)]. Error bars represent SEM. TZ, Target zone; $C$, caudal; L, lateral.
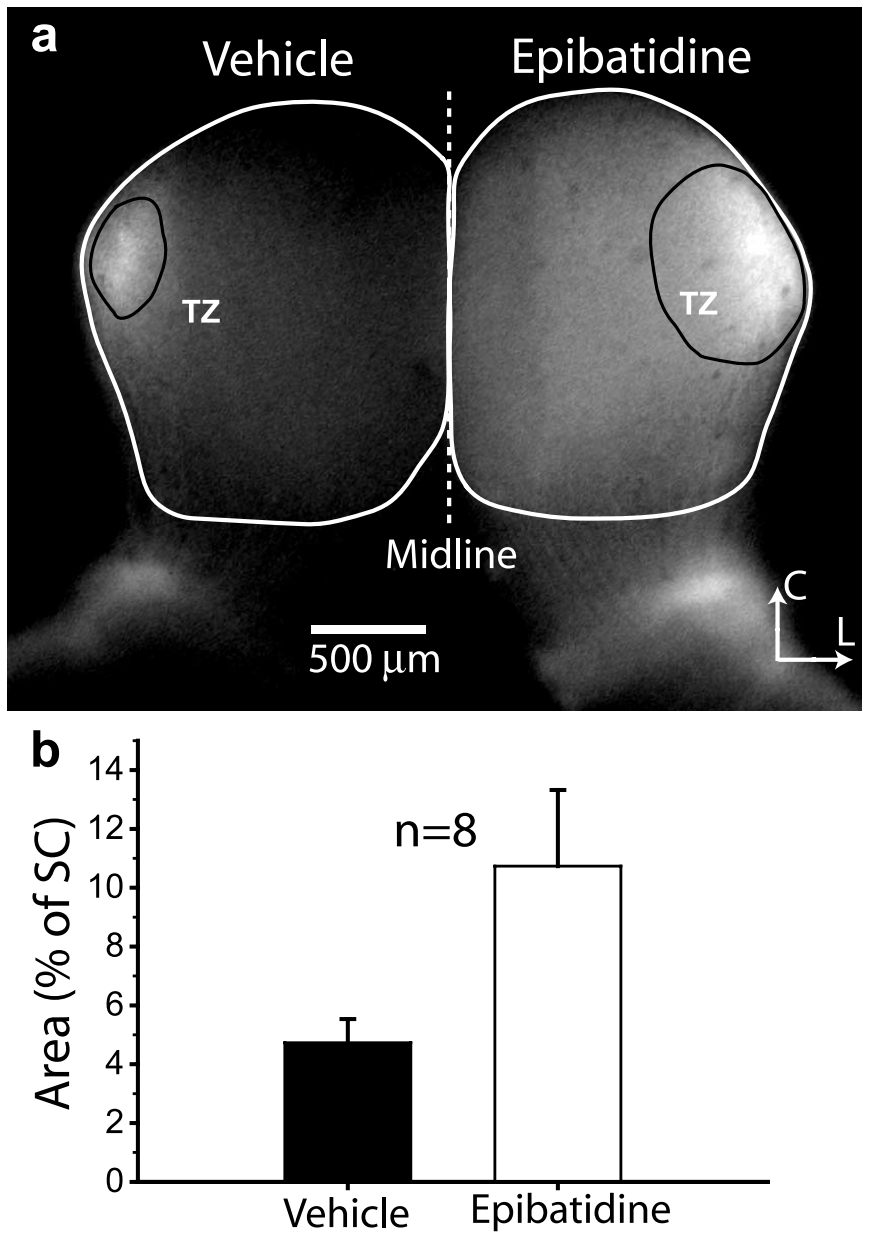

Figure 3. Epibatidine treatment to retina of WT mice mimics the phenotype of $\beta 2^{-1-}$ whole-animal K0. $\boldsymbol{a}$, Epibatidine was applied to one eye from P3-P7, with vehicle control treatment in the other eye. Focal dye injections at P7 result in larger projections to the $\mathrm{SC}$ contralateral to the epibatidine-treated eye than the SC contralateral to the vehicle-treated eye. Example of projections to the SC in a WT mouse from an eye treated with epibatidine (right) compared with projections to the $\mathrm{SC}$ in the same animal from an eye treated with vehicle solution (left). The labeled projection to the right SC, receiving input primarily from the epibatidine-treated eye, is significantly broader than the projection to the left $\mathrm{SC}$, receiving input primarily from the vehicle-treated eye. $\boldsymbol{b}$, Quantification from eight mice similarly treated in both eyes with either vehicle (black bar) or drug (white bar) reveals that epibatidine treatment results in larger projections from the retina to the $S C$ (paired $t$ test; $p<0.05$ ). Error bars represent SEM. TZ, Target zone; C, caudal; L, lateral.

expresses BMP in the eye (Hung et al., 2002), causing ventral RGC axons to take on a dorsal RGC fate (Plas et al., 2001). Normally, BMP is expressed in a high-dorsal to low-ventral gradient in the developing eye (Koshiba-Takeuchi et al., 2000; Murali et al., 2005). The graded expression of the BMP morphogen is thought in turn to induce the establishment of specific regional features of the retina, including the expression of gradients of axon guidance factors such as EphB and ephrinB that promote the formation of topographic maps in retinorecipient areas of the brain (McLaughlin et al., 2003a).

Ventral RGC axons in BMP transgenic mice express inappropriate levels of chemical guidance factors that are appropriate for dorsal RGC axons (Plas et al., 2001). As a result, ventral RGCs inappropriately project to collicular locations lateral to their normal target zone, where dorsal axons usually project (Fig. 2d,e) (3.7 \pm 0.4 ectopic spots covering $27.4 \pm 5.7 \%$ of SC area; $n=7)$. Injections into dorsal retina in $\mathrm{P} 6 / 7 \mathrm{BMP}$ transgenics that are 

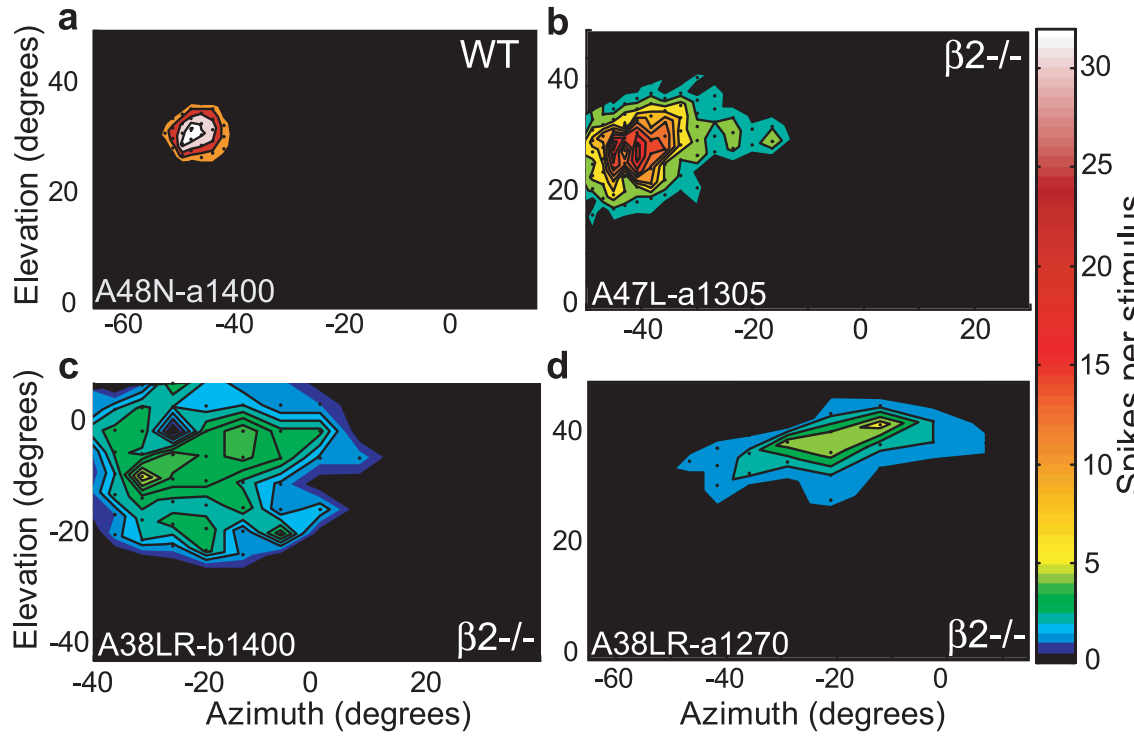

Figure 4. Enlarged in vivo RFs in the superior colliculus of $\beta 2^{-1-}$ mutant mice. $\boldsymbol{a}$, Typical multiunit receptive field in a WT mouse. The RF is compact, and response to stimulation of the RF center is large. $\boldsymbol{b}$, Typical multiunit response in a $\beta 2^{-1-}$ mouse. c, Example of a patchy receptive field of an isolated single neuron in a $\beta 2^{-/-}$mouse (Pearson's regression coefficient for $2 D$ Gaussian of $r^{2}=0.32$, indicating a very poor fit). $\boldsymbol{d}$, Elongated RF in isolated $\beta 2^{-1-}$ neuron. Mutant RFs are generally elongated along the nasal-temporal visual axis. Color scale bar on the right applies to all panels. Small black dots in each panel indicate spacing of visual stimuli.

evaluated $48 \mathrm{~h}$ later label a normal small target zone in lateral colliculus ( $2.7 \pm 0.3 \%$; no ectopic spots in $n=5$ animals) (Fig. $2 a, e)$. Focal injections into dorsal retina in BMP transgenics that are crossed onto a $\beta 2^{-1-}$ background $\left(\beta 2^{-1-} ; \mathrm{BMP}\right)$ result in a single enlarged target zone in lateral colliculus $(20.4 \pm 1.6 \%$; $n=$ 4) (Fig. $2 b, e$ ), as would be expected because of the absence of refinement via $\beta 2$-mediated retinal waves in these mice. However, focal injections of dye into ventral retina of $\beta 2^{-/-}$;BMP mice, instead of producing a similarly expanded, but shifted target zone in the colliculus, produce a single dramatically enlarged target zone that nearly fills the colliculus $(77.0 \pm 2.1 \% ; n=3 ; p<$ 0.001 ) (Fig. $2 c, e$ ). Thus, even in the absence of molecular cues responsible for RGC axon guidance, spontaneous retinal waves cause the refinement of mistargeted retinal axons and the formation of small ectopic spots of misdirected axons in the colliculus. Elimination of spontaneous retinal waves in mutants with RGC axon guidance defects has a dramatic cumulative effect on topography that results in grossly mistargeted and unrefined retinal projections to the superior colliculus.

\section{Epibatidine treatment mimics $\beta 2$ mutant phenotype}

In situ hybridization in WT mice for the $\beta 2$ subunit of $\mathrm{nAChRs}$ showed that $\beta 2$ is widely distributed in the CNS during the first postnatal week, including heavy expression in the superficial layers of the SC at P7 (www.genepaint.org; GenePaint set ID: HB272). Therefore, the deficit in topographic refinement of RGC axons in $\beta 2$ mutants could be because of postsynaptic effects in the SC rather than a lack of spontaneous activity in the retina. To clarify this issue, we pharmacologically blocked nAChRmediated retinal activity in WT mice during development with daily vitreal injections of epibatidine. Epibatidine is an nAChR agonist that blocks retinal waves in vitro (Kittila and Massey, 1997) by desensitizing the receptor.

DiI injections at P6/7 into the retina of epibatidine-treated eyes resulted in significantly larger SC target zones than DiI in- jections into vehicle-treated eyes in the same animal $(4.73 \pm 0.81 \%$ in control; $10.73 \pm 2.59 \%$ in epibatidine; $n=8$ animals; paired $t$ test; $p<0.05$ ) (Fig. 3 ). The size of the RGC target zone in the epibatidine-treated mice was somewhat smaller than that in the $\beta 2^{-1-}$ mice, possibly because the daily injections could not start until P3, and earlier retinal activity may play an important role in refinement. Nonetheless, this result demonstrates that blockade of cholinergic activity in the retina is sufficient to inhibit RGC axon refinement.

\section{Large in vivo receptive fields in $\boldsymbol{\beta 2}{ }^{-l-}$ mice}

We used in vivo single-unit and multiunit electrophysiological techniques to investigate the physiological consequences of eliminating neonatal retinal waves on the development of retinotopy in the SC. Neuronal responses to visual stimuli were used to reconstruct RFs in $\beta 2^{-1-}$ mice and their littermates. Recordings were obtained from a total of $23 \mathrm{WT}, 39 \beta 2^{+/-}$, and $17 \beta 2^{-/-}$sites (from 12, 16, and 11 animals, respectively). RF centers varied between -10 and 50 degrees elevation and -60 and 15 degrees azimuth. There was no systematic difference in the distribution of RF centers between genotypes (data not shown). Moreover, magnification is relatively uniform across the superior colliculus in the mouse compared with large mammals; thus, there is little effect of retinal position on RF size (McIlwain, 1975; Drager and Hubel, 1975).

Receptive fields in WT and $\beta 2^{+/-}$mice were typically circular and compact (Fig. 4a), and responses were usually well fit with a single oriented 2D (elliptical) Gaussian (mean Pearson's $r^{2}$ for WT and $\beta 2^{+/-}$multiunits of $0.87 \pm 0.05, n=20$ and $0.82 \pm 0.04$, $n=38$, respectively) (Fig. $5 a$ ). In contrast, receptive fields in $\beta 2^{-l-}$ mice were large, elongated, and sometimes patchy (Fig. $4 b-d)$. Gaussian fits in the $\beta 2^{-/-}$mice were, on average, significantly worse (mean Pearson's $r^{2}$ for $\beta 2^{-/-}$multiunits of $0.58 \pm$ $0.07, n=15, p<0.01$ ) (Fig. $5 a$ ), reinforcing the impression of disorganized RFs in the mutant mice. We used two methods to compute RF area (see Materials and Methods). First, for RFs that were well fit with a Gaussian (Pearson's $r^{2}>0.5$ ), we computed the area with response $>37 \%$ of the calculated Gaussian peak (WT, $165 \pm 21 \mathrm{deg}^{2}, n=19 ; \beta 2^{+/-}, 170 \pm 22 \mathrm{deg}^{2}, n=34$; $\beta 2^{-l-}, 1046 \pm 352 \mathrm{deg}^{2}, n=10$ ). Because 2D (elliptical) Gaussians sometimes proved to be poor fits to the data, especially in the $\beta 2$ mutants, we also summed the area of the stimulation sites that yielded responses $>37 \%$ of the peak response, independent of a Gaussian fit (data not shown). With both methods, RFs in the mutants were dramatically larger than the WT or $\beta 2^{+/-}$receptive fields (Fig. 5b) ( $p \ll 0.001)$. A separate analysis of isolated single units reveals results very similar to the multiunit analysis, showing that receptive fields from neurons in $\beta 2^{-1-}$ mice are not as well fit by a 2D Gaussian [mean Pearson's $r^{2}$ for WT and $\beta 2^{+/-}$ of $0.90 \pm 0.02, n=9 ; \beta 2^{-1-}, 0.65 \pm 0.07, n=10$ (Fig. $5 a$ ); $p<$ $0.01]$ and have significantly larger RFs than WT and $\beta 2^{+/-}$neurons [WT and $\beta 2^{+/-}, 197 \pm 32 \mathrm{deg}^{2}, n=9 ; \beta 2^{-1-}, 870 \pm 321$ $\operatorname{deg}^{2}, n=9$ (Fig. 5b); $p<0.05$ ]. 
Smaller peak response but similar total response of neurons in $\beta 2^{-/-}$mice It was generally more difficult to evoke visual responses in the $\beta 2^{-1-}$ mice than in WT or $\beta 2^{+/-}$littermates. This is reflected in significantly smaller peak response in mutant mice than WT and $\beta 2^{+/-}$controls (Figs. $4,5 c$ ) (WT, $30.3 \pm 2.9$ spikes, $n=19$; $\beta 2^{+/-}, 32.3 \pm 2.5$ spikes, $n=34 ; \beta 2^{-1-}$, $11.1 \pm 1.6$ spikes, $n=10 ; p \ll 0.001)$. However, the total response, defined as the product of the stimulus area times the neuronal response summed over all visual field stimulus locations (see Materials and Methods), was not significantly different between genotypes (Fig. $5 d$ ) (WT, $3088 \pm$ 477 spikes-deg $^{2}, n=19 ; \beta 2^{+/-}, 3366 \pm$ 459 spikes-deg ${ }^{2}, n=34 ; \beta 2^{-1-}, 6519 \pm$ 2321 spikes-deg $\left.{ }^{2}, n=10\right)$. These results suggest that the total number of RGC inputs to a neuron in the superior colliculus of $\beta 2$ mutants is the same as that in WT animals, but inputs are sparser and spread over a larger area in $\beta 2^{-l-}$ mutants. These trends were observed in isolated single units as well (WT and $\beta 2^{+/-}$peak response, $40.2 \pm 9.6$ spikes, $n=9 ; \beta 2^{-1-}$ peak response, $4.7 \pm 0.3$ spikes, $n=9, p<$ 0.01 ; WT and $\beta 2^{+/-}$total response, $4038 \pm 572$ spikes-deg ${ }^{2}, n=9 ; \beta 2^{-1-}$ total response, $2701 \pm 1053$ spikes-deg ${ }^{2}$, $n=9)$.

$\beta 2^{-/-}$receptive fields are preferentially elongated along the nasal-temporal axis We examined the projection of the receptive field along the nasal-temporal (NT) and dorsal-ventral (DV) axis using 2D (elliptical) Gaussian fits (Fig. 6a). A cursory analysis suggests that receptive fields in WT and $\beta 2^{+/-}$animals are circular (Fig. $4 a$ ). In contrast, RFs in $\beta 2$ mutants appear elongated along the NT visual axis (Fig. 4d). These apparently elongated RFs could be an artifact of a preexisting trend for elongated RFs in WT colliculus that is accentuated by the larger RFs in $\beta 2^{-1-}$ mice but is not intrinsic to the mutant. A two-way ANOVA showed that RF size was significantly different between genotypes $(p \ll 0.001)$ and that there was also a significant difference between the NT and DV extent of the RFs, regardless of genotype ( $p \ll 0.001)$. However, neither of these observed differences accounts for all of the variance in the data, because there is a significant interaction between the axis of projection and genotype $(p \ll 0.001)$. This suggests that RFs in $\beta 2$ mutants are not just larger versions of already elongated RFs in WT mice. A paired $t$ test indicates that RFs in $\beta 2$ mutants were significantly elongated along the NT axis of visual space (Fig. $6 a, b)\left(\mathrm{WT}, p=0.06 ; \beta 2^{+/-}, p=0.02 ; \beta 2^{-1-}\right.$, $p \ll 0.001$ ), and an analysis of the projection ratios demonstrates that there was significantly more NT bias in the $\beta 2$ mutants than in the WT or $\beta 2^{+/-}$mice (Fig. $6 d$ ) (NT to DV projection ratio: $\mathrm{WT}, 1.14 \pm 0.06, n=22 ; \beta 2^{+/-}, 1.37 \pm 0.07, n=36 ; \beta 2^{-l-}$, $1.80 \pm 0.15, n=12$; $t$ test; $p<0.01$ between $\beta 2^{-1-}$ and WT or $\beta 2^{+/-}$).

We also analyzed the anatomical projections to the SC at P21 attributable to the focal injection of DiI into the retina by mea- suring the RC and ML extent of the collicular target zones (Fig. $1 e, f)$. Anatomical projections are elongated preferentially along the RC axis of the SC, which corresponds to the NT axis of visual space (Fig. 6c) (two-way ANOVA; $p<0.05$; interaction, $p<$ $0.05)$. This may be partially attributable to the proximity of the target zones to the lateral edge of the colliculus. Nonetheless, the anatomical projection ratio (ratio of RC to ML target zone extent) in mutant mice is higher than that of WT or $\beta 2^{+/-}$mice (WT, $1.49 \pm 0.11, n=4 ; \beta 2^{+/-}, 1.28 \pm 0.09, n=10 ; \beta 2^{-/-}$, $2.30 \pm 0.18, n=6$; $t$ test; $p<0.001$ between $\beta 2^{-1-}$ and WT or $\beta 2^{+/-}$). The abnormal anatomical and physiological (ratio of NT to DV receptive field size) projection ratios (Fig. $6 d$ ) highlight the asymmetric effect of blocking retinal waves on mapping along the NT axis of visual space, corresponding to the RC axis of the superior colliculus.

\section{Discussion}

We demonstrated that, in the absence of spontaneous retinal waves, the refinement of RGC axon arbors into a precise retinotopic map in the superior colliculus of the mouse was dramatically degraded, although the gross topography of the retinocollicular projection appeared normal. Refinement partially recovered after the first postnatal week in the $\beta 2^{-/-}$mice, but no additional refinement was observed after P14, when the eyelids opened. We also found that the formation of focal ectopic spots, 
a Projection along each visual axis $\mathbf{b}$
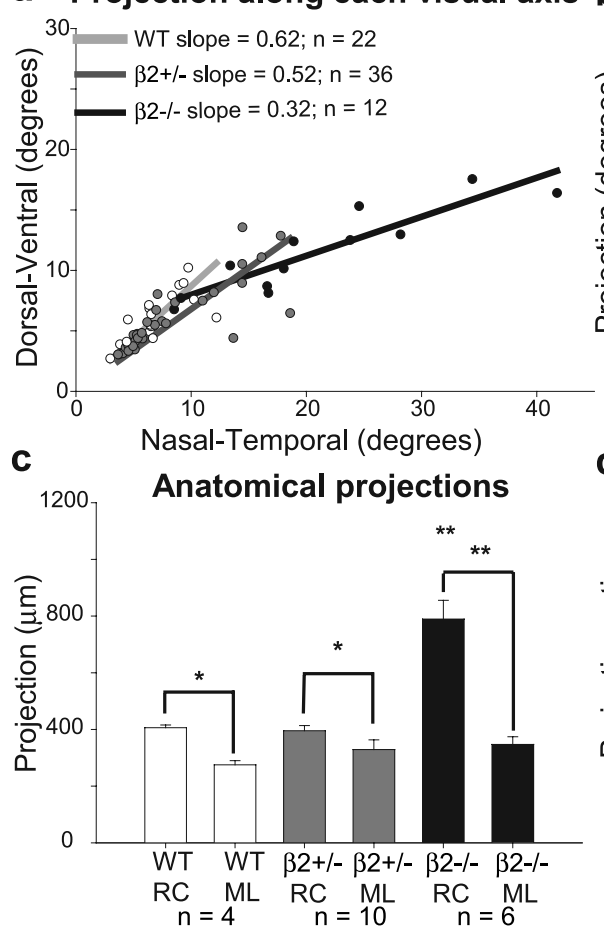

d
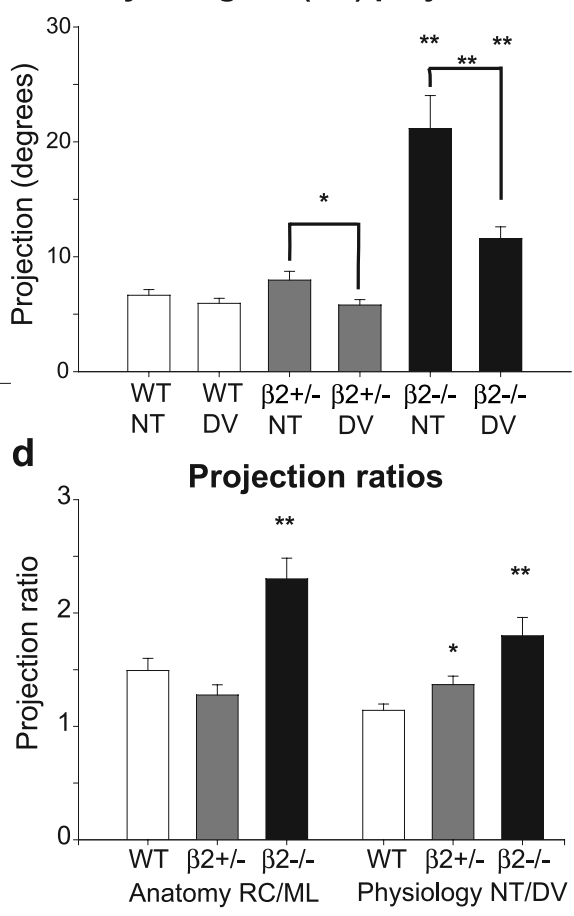

Figure 6. Retinocollicular projections are preferentially elongated along the NT axis of the retina in $\beta 2^{-1-}$ mutant mice. $\boldsymbol{a}$, Scatterplot of dorsoventral versus nasal-temporal RF projections in WT (open circles), $\beta 2^{+/-}$(gray circles), and $\beta 2^{-1-}$ (black circles) mice. $\beta 2^{-I-}$ RFs are larger and more elongated along the NT axis. Numbers include all well fit sites with multiunit response in addition to sites with only single-unit response. $\boldsymbol{b}$, Paired comparisons of the NT and DV projections show a significant difference in the $\beta 2^{+/-}$and $\beta 2^{-1-}$ mice (paired $t$ test; WT, $p=0.06 ; \beta 2^{+/-},{ }^{*} p=0.02 ; \beta 2^{-1-},{ }^{* *} p \ll 0.001$ ). The projections along each axis are also significantly larger in the $\beta 2^{-/-}$compared with WT or $\beta 2^{+/-}$mice $\left(t\right.$ test; $\left.{ }^{* *} p<0.001\right)$. c, A similar measurement of the anatomical projections to the SC for P21 mice reveals a corresponding bias in the projections along the $\mathrm{RC}$ axis of the $\mathrm{SC}$, which corresponds to the NT axis in visual space (paired $t$ test; $\beta 2^{+/-},{ }^{*} p<0.05$; WT, ${ }^{*} p<0.01 ; \beta 2^{-1-}$, ${ }^{* *} p<0.001$ ). Although the rostrocaudal projections of the mutant are significantly larger than the corresponding WT and $\beta 2^{+/-}$projections $\left(t\right.$ test; $\left.{ }^{* *} p<0.001\right)$, there is no difference between the mediolateral projections between genotypes. $\boldsymbol{d}$, $\boldsymbol{T}$ the ratio of the RC/ML anatomical projection in $\beta 2^{-/-}$mice is significantly higher than in WT ( $t$ test; ${ }^{* *} p<0.01$ ) or $\beta 2^{+/-}$( $t$ test; $\left.{ }^{* *} p<0.001\right)$ mice. The ratio of the physiological response along the NT/DV axis is significantly different between WT and $\beta 2^{+/-}$ mice $\left({ }^{*} p=0.03\right)$ and highly significant between WT and $\beta 2^{-/-}\left({ }^{* *} p \ll 0.001\right)$ or between $\beta 2^{+/-}$and $\beta 2^{-/-}\left(^{* *} p<\right.$ $0.01)$ mice. This highlights the asymmetric effect of blocking retinal waves on mapping along the nasal-temporal axis of visual space. Error bars represent SEM.

a ubiquitous phenotype in mutants with axon guidance defects, is attributable to a process of activity-dependent refinement that is driven by retinal waves and mediated by glutamate receptors at retinocollicular synapses. Finally, in accord with the anatomical experiments, in vivo RFs of neurons in the colliculus of $\beta 2^{-/-}$ mice are dramatically enlarged, particularly along the NT axis of the retina. In total, these experiments describe how molecular and activity-dependent mechanisms combine to mediate the development of retinotopic maps in the colliculus and show the necessity for spontaneous retinal waves in the development of retinotopically precise RFs.

Retinotopic map refinement is instructed by retinal waves The postnatal application of NMDA receptor antagonists to the colliculus impairs retinotopic refinement (Simon et al., 1992; Huang and Pallas, 2001), arguing that map refinement requires glutamatergic signaling in the colliculus. These experiments, however, do not address whether this signaling occurs between collicular neurons or through retinocollicular synapses. We demonstrated that map refinement is impaired in mice that lack retinal waves, arguing specifically that retinocollicular activity is necessary for map refinement. The $\beta 2^{-1-}$ mice, which lack spon- taneous retinal waves, still show nearly normal levels of spontaneous uncorrelated ganglion cell activity (Bansal et al., 2000; McLaughlin et al., 2003b). Impaired retinotopic maps in the colliculus of $\beta 2^{-1-}$ mice demonstrate that retinal activity is not simply permissive in the process of retinocollicular map refinement, because activity levels are nearly normal in the ganglion cells of $\beta 2^{-1-}$ mutants. Rather, the temporal pattern of ganglion cell activity generated by spontaneous retinal waves is instructive in the process of retinotopic map refinement (Crair, 1999), presumably because wave activity is highly correlated in neighboring retinal ganglion cells. We also observed a partial rescue of map refinement in the second week after birth in the in $\beta 2^{-1-}$ mice, most likely because of the onset of glutamate receptor-mediated retinal waves, which, in $\beta 2^{-1-}$ mice, replace the missing nAChR-mediated waves at approximately P8 (Bansal et al., 2000). A recent report describes similar results in young (approximately P7) $\beta 2^{-/-}$mice (McLaughlin et al., 2003b). However, refinement of the retinotopic map between P7 and P21 did not reach statistical significance in that report. The partial refinement we observed of retinocollicular projections attributable to glutamate receptor-mediated waves in the second week after birth may be analogous to the "local" islands of like-eye response that emerge in the LGN of $\beta 2$ mutants at the same age (Muir-Robinson et al., 2002).

\section{Pharmacological blockade of $\beta 2$}

nAChRs in WT retina mimics $\beta 2$ whole-animal knock-outs

The interpretation of experiments that rely on the $\beta 2$ whole-animal knock-out (KO) model is confused by the presynaptic and postsynaptic expression of the $\beta 2$ subunit during development. We partially addressed this issue by pharmacologically blocking nAChR-mediated synaptic transmission only in the retina of wild-type mice. This pharmacological intervention was shown previously to eliminate all retinal activity (Penn et al., 1998), whereas spontaneous uncorrelated ganglion cell firing is still present in the retinas of $\beta 2^{-1-}$ mice (McLaughlin et al., 2003b). Refinement in WT mice with pharmacologically blocked nAChR activity in the retina was incomplete (Fig. 3) but not as poor as that in the $\beta 2^{-l-}$ mice. This could be because the pharmacological intervention was imperfect or because postsynaptic $\beta 2$ receptors contribute to the KO phenotype. In fact, some have argued for the LGN that retinal waves are merely permissive (Huberman et al., 2002, 2003), but not instructive (Shatz and Stryker, 1988; Cook et al., 1999), in the process of RGC axon refinement, and the lack of refinement is attributable to the absence of $\beta 2$ receptors in the target, in which nAChRs positively modulate visual response (Tu et al., 2000). Definitive resolution of this issue awaits the development of region (retina or LGN/ $\mathrm{SC})$-specific knock-outs of the $\beta 2$ receptor in mice. 
Enlarged receptive fields in $\beta 2^{-1-}$ mice

We observed a significant increase in RF size in the $\beta 2$ mutants compared with littermate controls, consistent with the enlarged anatomical projections observed between the retina and SC. It is unlikely that the enlarged RFs observed in the SC of juvenile $\beta 2$ mutants are attributable to an intrinsic effect of $\beta 2$ receptors on retinal function, because retinal anatomy is normal in adult $\beta 2$ mutants (Bansal et al., 2000), and the spatial frequency threshold to evoke pattern ERGs from the retina of $\beta 2^{-1-}$ are normal (Rossi et al., 2001). We also observed a decrease in the peak firing rate of collicular neurons in the $\beta 2$ mutants. This suggests that individual inputs to collicular neurons are weaker, but it could also reflect a decrease in the peak firing rate of RGCs in $\beta 2 \mathrm{mu}-$ tants or the absence of positive modulation by presynaptic nAChRs in the colliculus ( $\mathrm{Tu}$ et al., 2000). The enlarged and sometimes patchy RFs observed in juvenile $\beta 2^{-/-}$mice are similar to those observed in the immature LGN (Tavazoie and Reid, 2000) and SC (Carrasco et al., 2003) and the disordered retinotopic maps in adult $\beta 2^{-1-}$ mice revealed with optical imaging techniques (Mrsic-Flogel et al., 2005), further suggesting that $\beta 2^{-I-}$ RFs are poorly refined.

Surprisingly, no increase in RF size or decrease in the amplitude of visual response was reported in the LGN of $\beta 2$ mutants (Grubb et al., 2003), despite abnormally large RGC projections to the LGN and the dramatic disruption in eye-specific segregation of RGC afferents (Rossi et al., 2001; Muir-Robinson et al., 2002). This could be because neurons in the adult LGN receive input from only one or two RGCs (Usrey et al., 1999; Chen and Regehr, 2000), whereas neurons in the SC are thought to receive input from 10 or more RGCs (Finlay and Pallas, 1989). In the LGN, activity may instruct the process of choosing the retinotopically appropriate RGC, but the number of RGC inputs is limited to one or two by a mechanism that is not dependent on visually evoked activity (Hooks and Chen, 2004). In the colliculus, however, there is significant convergence of RGC inputs even in the adult, which, in the absence of activity-dependent instruction, results in scattered retinal input and abnormally large collicular RFs. On average, the total response from across the retina is similar in $\beta 2$ mutants and WT controls. However, the anatomical refinement of RGC arbors in WT mice concentrates afferent input to a limited region of the SC, resulting in larger peak response and smaller RFs in WT mice. The preservation of total response levels in $\beta 2$ mutants could be the result of a homeostatic mechanism that maintains a similar quantity of synaptic input to collicular neurons even in the absence of spatial refinement.

\section{Implications of asymmetric mapping of the DV and NT axis of the retina}

We observed a significant asymmetry in the $\beta 2$ mutants on the effect of activity-dependent retinotopic refinement between the NT and DV axis, so that DV axis refinement was only modestly disturbed in the SC, whereas NT axis refinement was dramatically disturbed. This suggests that mechanisms for the formation of NT and DV retinotopy are separable, with mapping of the NT axis particularly dependent on activity. This is consistent with findings in many species (Springer and Mednick, 1983; Rager et al., 1988; Reese and Baker, 1993; Chan and Guillery, 1994), including the mouse (Plas et al., 2005), that axons from the DV axis of the retina are already mapped in the optic tract before they enter their target, but axons from the NT axis are completely mixed. Interestingly, a similar asymmetry was observed in the LGN of $\beta 2$ mutants, in which the primary effect of the $\beta 2$ mutation on retinotopy was a blurring of fine scale topography along

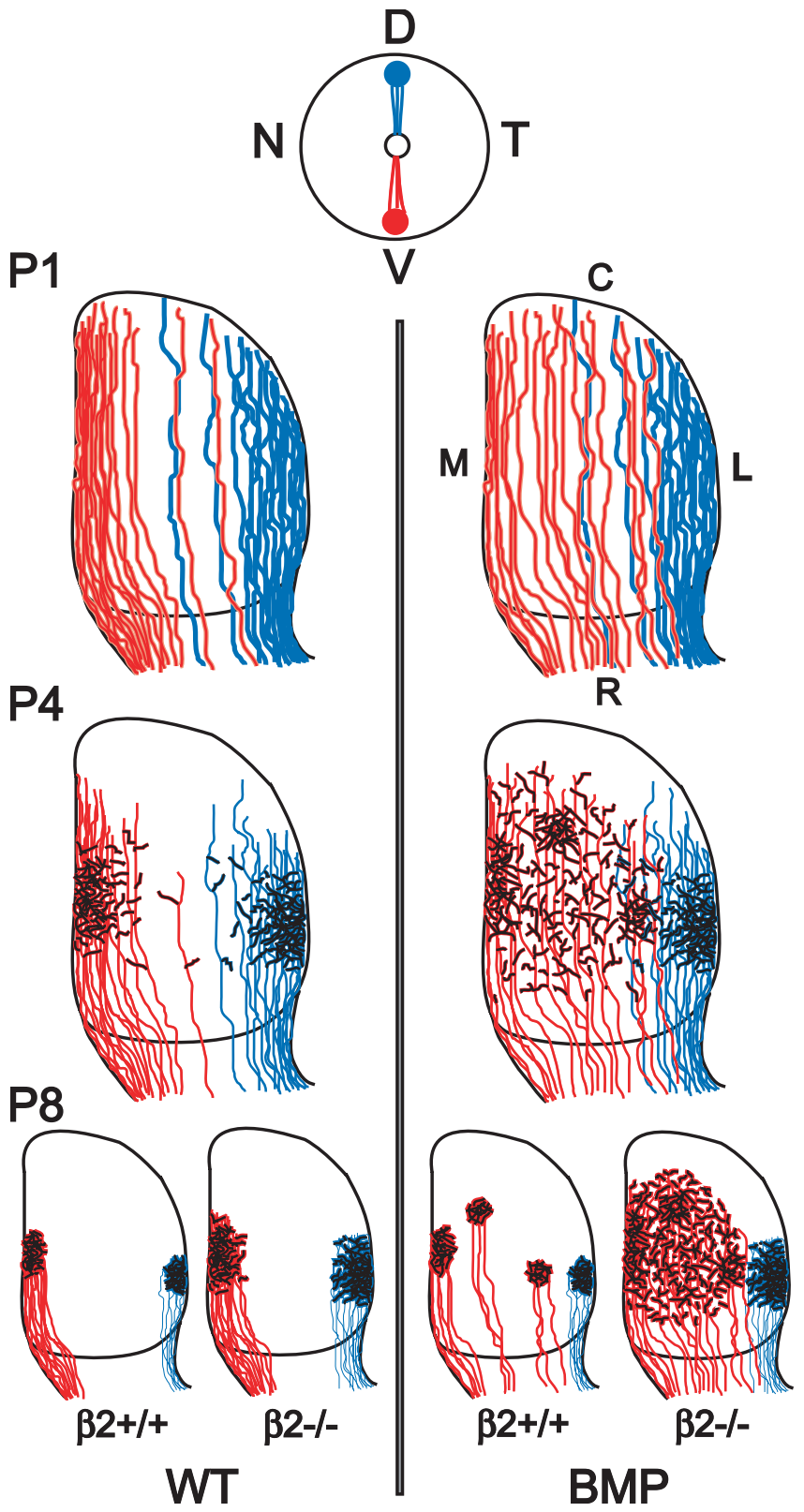

Figure 7. Model for the combined effect of molecular and activity-dependent factors on retinotopic map development. Early in development (P1), retinal ganglion cells rely on axon guidance cues to target themselves to the colliculus. Illustrated are axons from dorsal (blue) and ventral (red) retina. In BMP transgenic mice (right column), these molecular cues are inappropriate for ventral axons; thus, their targeting in the colliculus is disrupted. During the first week after birth (between P1 and P8), retinal axons arborize preferentially along the rostrocaudal axis at a location determined by their nasal-temporal position in the retina. In BMP transgenic mice, the increased spread of ventral retinal axons along the mediolateral extent of the colliculus results in ventral arbors covering a large fraction of the colliculus. By P8, correlated retinal waves have refined the projection of retinal ganglion cell arbors to a retinotopically appropriate focal region in the colliculus. In the absence of retinal waves (left column, $\beta 2^{-1-}$ ), the projection pattern is left in an unrefined, immature state. In mutants with axon guidance defects but intact retinal waves (right column, $\beta 2^{+/+}$), activity-dependent Hebbian mechanisms mutually reinforce a small number of misprojecting (ventral) axons into refined focal ectopic spots. Dorsal retinal axons refine normally. In the absence of correlated activity in the retina (right column, $\beta 2^{-I-}$ ), dorsal (blue) axons in BMP transgenic mice target appropriately but do not refine into a focal spot. In the absence of both correlated activity and appropriate axon guidance cues, ventral (red) axons in the $\beta 2^{-1-} ; \mathrm{BMP}$ mice make widespread projections that remain in an immature exuberant state. D, Dorsal; T, temporal; V,ventral; N, nasal; C, caudal; L, lateral; R, rostral; $M$, medial. 
the NT axis but not the DV axis (Grubb et al., 2003). Thus, activity-dependent mechanisms at the target (LGN/SC), perhaps working in coordination with Eph/ephrin signaling (Cline, 2003; Xu et al., 2003; Yamaguchi and Pasquale, 2004), play a larger role in mapping and refinement of the NT axis of the retina than the DV axis.

It is interesting to speculate on the consequences of increased RF size in the SC on the behavior of $\beta 2$ mutant mice. Merely increasing RF size need not have a detrimental effect on orienting responses, because population coding models in the SC perform well when tuning becomes broader (Baldi and Heiligenberg, 1988). However, the preferential expansion of RFs along one axis could have an effect, with a large number of neurons activated almost equally along the representation of the azimuth (NT axis of the eye). This suggests that the ability to make accurate orienting movements will be poorer for targets along the azimuth (NT) than those differing in elevation (DV axis of the eye). All of this assumes that the changes in activity observed in superficial layers of the SC is reflected in the activity of deeper output neurons.

\section{Molecular and activity-dependent cues work together in constructing retinotopy}

We used a BMP transgenic mouse, with disturbed axon guidance of ventral, but not dorsal, retinal ganglion cell axons (Hung et al., 2002; Murali et al., 2005) (Plas et al., 2001), to examine how molecular and activity-dependent mechanisms work together to create retinotopic maps in the SC. By crossing the BMP transgenics onto a $\beta 2^{-1-}$ background, we evaluated the combined effects of chemotropic and activity-dependent factors on the development of retinotopy. We showed that neither factor by itself was sufficient to achieve normal retinotopy and that disturbing both in the same axons had striking cumulative affects. Our data can be summarized with a simple model (Fig. 7) in which chemotropic factors mediate the initial crude topographic order of retinal ganglion cell axon projections to the SC, and spontaneous retinal activity then locally refines the coarse topographic branching of axons to a common focal retinotopic target. This model can explain results from WT animals, BMP mutants, $\beta 2^{-1-}$ mutants, and the combined $\beta 2^{-1-} ;$ BMP double mutants. Mice with axon guidance defects may develop ectopic spots because activity mediates a local Hebbian process in which similarly misprojecting axons locally reinforce each other, leaving a focal island of initially misdirected axons. Mutants without spontaneous retinal waves have relatively broad projections, because molecular factors by themselves are insufficient to mediate the local refinement of axon arbors into focal target zones. In the absence of guidance by both molecular and activity-dependent cues, retinal ganglion cell projections to the colliculus are extremely diffuse. This is a vivid demonstration, in the same axons within the same neural structure, of the combined effects of activity-dependent and molecular cues in the process of neural circuit development. Many questions remain about details in this process, but these experiments should provide an important framework for future research examining the interaction between activity and molecular factors in brain development.

\section{References}

Baldi P, Heiligenberg W (1988) How sensory maps could enhance resolution through ordered arrangements of broadly tuned receivers. Biol Cybern 59:313-318.

Bansal A, Singer JH, Hwang BJ, Xu W, Beaudet A, Feller MB (2000) Mice lacking specific nicotinic acetylcholine receptor subunits exhibit dramatically altered spontaneous activity patterns and reveal a limited role for retinal waves in forming $\mathrm{ON}$ and $\mathrm{OFF}$ circuits in the inner retina. J Neurosci 20:7672-7681.

Carrasco MM, Razak KA, Pallas SL (2003) Effects of dark-rearing on retinocollicular map refinement. Soc Neurosci Abstr 29:37.23.

Chan SO, Guillery RW (1994) Changes in fiber order in the optic nerve and tract of rat embryos. J Comp Neurol 344:20-32.

Chen C, Regehr WG (2000) Developmental remodeling of the retinogeniculate synapse. Neuron 28:955-966.

Cline H (2003) Sperry and Hebb: oil and vinegar? Trends Neurosci 26:655-661.

Cook PM, Prusky G, Ramoa AS (1999) The role of spontaneous retinal activity before eye opening in the maturation of form and function in the retinogeniculate pathway of the ferret. Vis Neurosci 16:491-501.

Crair MC (1999) Neuronal activity during development: permissive or instructive? Curr Opin Neurobiol 9:88-93.

Debski EA, Cline HT (2002) Activity-dependent mapping in the retinotectal projection. Curr Opin Neurobiol 12:93-99.

Drager UC, Hubel DH (1975) Physiology of visual cells in mouse superior colliculus and correlation with somatosensory and auditory input. Nature 253:203-204.

Feldheim DA, Kim YI, Bergemann AD, Frisen J, Barbacid M, Flanagan JG (2000) Genetic analysis of ephrin-A2 and ephrin-A5 shows their requirement in multiple aspects of retinocollicular mapping. Neuron 25:563-574.

Feldheim DA, Nakamoto M, Osterfield M, Gale NW, DeChiara TM, Rohatgi R, Yancopoulos GD, Flanagan JG (2004) Loss-of-function analysis of EphA receptors in retinotectal mapping. J Neurosci 24:2542-2550.

Feller MB (2002) The role of nAChR-mediated spontaneous retinal activity in visual system development. J Neurobiol 53:556-567.

Finlay BL, Pallas SL (1989) Control of cell number in the developing mammalian visual system. Prog Neurobiol 32:207-234.

Flanagan JG, Vanderhaeghen P (1998) The ephrins and Eph receptors in neural development. Annu Rev Neurosci 21:309-345.

Grubb MS, Rossi FM, Changeux JP, Thompson ID (2003) Abnormal functional organization in the dorsal lateral geniculate nucleus of mice lacking the beta 2 subunit of the nicotinic acetylcholine receptor. Neuron 40:1161-1172.

Hooks BM, Chen C (2004) The role of visual experience in retinogeniculate synaptic development. Soc Neurosci Abstr 30:597.10.

Huang L, Pallas SL (2001) NMDA antagonists in the superior colliculus prevent developmental plasticity but not visual transmission or map compression. J Neurophysiol 86:1179-1194.

Huberman AD, Stellwagen D, Chapman B (2002) Decoupling eye-specific segregation from lamination in the lateral geniculate nucleus. J Neurosci 22:9419-9429.

Huberman AD, Wang GY, Liets LC, Collins OA, Chapman B, Chalupa LM (2003) Eye-specific retinogeniculate segregation independent of normal neuronal activity. Science 300:994-998.

Hung FC, Zhao S, Chen Q, Overbeek PA (2002) Retinal ablation and altered lens differentiation induced by ocular overexpression of BMP7. Vision Res 42:427-438.

Katz LC, Shatz CJ (1996) Synaptic activity and the construction of cortical circuits. Science 274:1133-1138.

Kittila CA, Massey SC (1997) Pharmacology of directionally selective ganglion cells in the rabbit retina. J Neurophysiol 77:675-689.

Koshiba-Takeuchi K, Takeuchi JK, Matsumoto K, Momose T, Uno K, Hoepker V, Ogura K, Takahashi N, Nakamura H, Yasuda K, Ogura T (2000) Tbx5 and the retinotectum projection. Science 287:134-137.

McIlwain JT (1975) Visual receptive fields and their images in superior colliculus of the cat. J Neurophysiol 38:219-230.

McLaughlin T, Hindges R, O’Leary DD (2003a) Regulation of axial patterning of the retina and its topographic mapping in the brain. Curr Opin Neurobiol 13:57-69.

McLaughlin T, Torborg CL, Feller MB, O’Leary DD (2003b) Retinotopic map refinement requires spontaneous retinal waves during a brief critical period of development. Neuron 40:1147-1160.

Mrsic-Flogel TD, Hofer SB, Creutzfeldt C, Cloëz-Tayarani I, Changeux J-P, Bonhoeffer T, Hübener M (2005) Altered map of visual space in the superior colliculus of mice lacking early retinal waves. J Neurosci 25 : 6921-6928.

Muir-Robinson G, Hwang BJ, Feller MB (2002) Retinogeniculate axons un- 
dergo eye-specific segregation in the absence of eye-specific layers. J Neurosci 22:5259-5264.

Murali D, Yoshikawa S, Corrigan RR, Plas DJ, Crair MC, Oliver G, Lyons KM, Mishina Y, Furuta Y (2005) Distinct developmental programs require different levels of Bmp signaling during mouse retinal development. Development 132:913-923.

O’Leary DD, Yates PA, McLaughlin T (1999) Molecular development of sensory maps: representing sights and smells in the brain. Cell 96:255-269.

Penn AA, Riquelme PA, Feller MB, Shatz CJ (1998) Competition in retinogeniculate patterning driven by spontaneous activity. Science 279:2108-2112.

Plas DT, Kim DS, Overbeek PA, Crair MC (2001) The role of BMP signaling in establishment of the dorsoventral axis in the retino-collicular projection. Soc Neurosci Abstr 27:592.1.

Plas DT, Visel A, Gonzalez E, She WC, Crair MC (2004) Adenylate Cyclase 1 dependent refinement of retinotopic maps in the mouse. Vision Res 44:3357-3364.

Plas DT, Lopez JE, Crair MC (2005) Pre-target sorting of retino-collicular axons in the mouse. J Comp Neurol, in press.

Rager U, Rager G, Kabiersch A (1988) Transformations of the retinal topography along the visual pathway of the chicken. Anat Embryol 179:135-148

Reese BE, Baker GE (1993) The re-establishment of the representation of the dorso-ventral retinal axis in the chiasmatic region of the ferret. Vis Neurosci 10:957-968.

Rossi FM, Pizzorusso T, Porciatti V, Marubio LM, Maffei L, Changeux JP (2001) Requirement of the nicotinic acetylcholine receptor beta 2 subunit for the anatomical and functional development of the visual system. Proc Natl Acad Sci USA 98:6453-6458.
Shatz CJ, Stryker MP (1988) Prenatal tetrodotoxin infusion blocks segregation of retinogeniculate afferents. Science 242:87-89.

Simon DK, O'Leary DD (1992) Development of topographic order in the mammalian retinocollicular projection. J Neurosci 12:1212-1232.

Simon DK, Prusky GT, O’Leary DD, Constantine-Paton M (1992) $\mathrm{N}$-methyl-D-aspartate receptor antagonists disrupt the formation of a mammalian neural map. Proc Natl Acad Sci USA 89:10593-10597.

Sperry RW (1963) Chemoaffinity in the orderly growth of nerve fiber patterns and connections. Proc Natl Acad Sci USA 50:703-710.

Springer AD, Mednick AS (1983) Dorsotemporal retinal ganglion cell axons of goldfish are located in the dorsal rather than ventral optic tract. Brain Res 273:152-155.

Tavazoie SF, Reid RC (2000) Diverse receptive fields in the lateral geniculate nucleus during thalamocortical development. Nat Neurosci 3:608-616.

Tu S, Butt CM, Pauly JR, Debski EA (2000) Activity-dependent regulation of substance $\mathrm{P}$ expression and topographic map maintenance by a cholinergic pathway. J Neurosci 20:5346-5357.

Usrey WM, Reppas JB, Reid RC (1999) Specificity and strength of retinogeniculate connections. J Neurophysiol 82:3527-3540.

Xu B, Li S, Brown A, Gerlai R, Fahnestock M, Racine RJ (2003) EphA/ ephrin-A interactions regulate epileptogenesis and activity-dependent axonal sprouting in adult rats. Mol Cell Neurosci 24:984-999.

Xu W, Orr-Urtreger A, Nigro F, Gelber S, Sutcliffe CB, Armstrong D, Patrick JW, Role LW, Beaudet AL, De Biasi M (1999) Multiorgan autonomic dysfunction in mice lacking the $\beta 2$ and the $\beta 4$ subunits of neuronal nicotinic acetylcholine receptors. J Neurosci 19:9298-9305.

Yamaguchi Y, Pasquale EB (2004) Eph receptors in the adult brain. Curr Opin Neurobiol 14:288-296. 